\title{
The Formation of Simplex Nouns in Urban Hijazi Arabic: A Distributed Morphology Approach
}

\author{
Thamir Al Barrag, Salih Alzahrani \\ Taif University, Taif, Saudi Arabia
}

\begin{abstract}
This paper investigates the structure of the simplex nouns in Hijazi Arabic following the Distributed Morphology (DM) framework. It is argued that simplex nouns are derived in the syntax from neutral root and morphosyntactic features in the same way phrases are. All nouns in Hijazi Arabic (HA) must inflect for gender and number. Moreover, all nouns can attach to the definite article al- "the". Hence, it is proposed that the functional heads (n)ominaliser, (Gen)der, (Num)ber, and (D)eterminer respectively c-command the neutral root and host the relevant feature value.
\end{abstract}

Keywords: Noun, Noun Phrase, Nominaliser, Gender, Number, DP, Hijazi Arabic, Distributed Morphology

\section{Introduction}

Since the determiner phrase (DP) Hypothesis was proposed by Abney (1987), the noun phrase (NP) is assumed to be headed by a determiner phrase (DP), in the same way that a verb phrase (VP) is headed by a complementiser phrase (CP). DPs and CPs are seen to have parallel properties in the sense that both of them contain functional heads $\mathrm{D}$ and $\mathrm{C}$ which c-command the lexical heads ( $\mathrm{N}$ and $\mathrm{V}$ respectively). Therefore, along the lines of Abney's (1987) proposal and subsequent works (Bernstein, 1991; Ritter, 1992; Longobardi, 1994; 2001; Bernstein, 2001 among many others), it will be argued that D is the head of the Hijazi Arabic (HA) NP and that it c-selects the NP as its complement. Thus, the DP in HA consists of a root that is c-commanded by four functional heads: (n)ominaliser, (Gen)der, (Num)ber, and (D)eterminer. The terms noun and $\mathrm{nP}$ will be used to refer to the syntactic constituent which consists of the root $(\sqrt{ })$ and the nominaliser head (n). Following the tradition in the literature, NP will be used to refer to the maximal projection headed by a determiner, DP.

This paper will focus on the basic structure of the NP in line with Distributed Morphology (DM). It comprises two main sections. In the first section, the discussion will be about the natural classes of nouns in terms of the noun classification system proposed in Jackendoff (1991). The main properties and characteristics of each class are briefly described. The aim of this section is to provide background to the following section where the different functional heads of the noun will be examined. We will refer to the different noun classes to show which one of them can be headed by which head and the conditions accompany that (if any).

The second section discusses the formation of simplex nouns in detail. It is argued in this paper that nouns in HA comprise a root that is c-commanded by four functional heads: (n)ominaliser, (Gen)der, (Num)ber, and (D)eterminer. Each of the above heads in association with the noun will be reviewed. Since roots in DM have

Thamir Al Barrag, Ph.D., Assistant Professor, Foreign Languages Department, Taif University, Taif, Saudi Arabia.

Salih Alzahrani, Ph.D., Assistant Professor, Foreign Languages Department, Taif University, Taif, Saudi Arabia. 
no grammatical features (Halle \& Marantz, 1993; 1994; Marantz, 1997; Harley \& Noyer, 1999; 2000; Pfau, 2000; 2009; Siddiqi, 2006; 2009; Embick \& Noyer, 2007; Embick, 2010; Haugen \& Siddiqi, 2013 among many others), it is argued that the noun's different grammatical features (e.g., gender, number, and definiteness) are distributed among the different functional heads.

\section{Nominal Classes}

Nouns can be classified on a morphosyntactic basis into count nouns and mass nouns. Count nouns have the following properties (Fassi Fehri, 2012, p. 121):

(1) a. a numeral property: A count $\mathrm{nP}$ can be (directly) modified by a numeral;

b. a number property: It supports grammatical number (singular, plural; dual or trial in languages that have one or both distinctions);

c. a count determiner property: It can be selected by a count determiner/quantifier (such as "every", "each", "several", "many", "few").

d. a classifier property: It is constructed with a (covert/overt) classifier in the presence of a numeral modifier.

Nouns that have the above properties are countable whereas those which lack these properties are considered mass nouns. Consider the examples in (2) and (3) for count and mass nouns respectively:

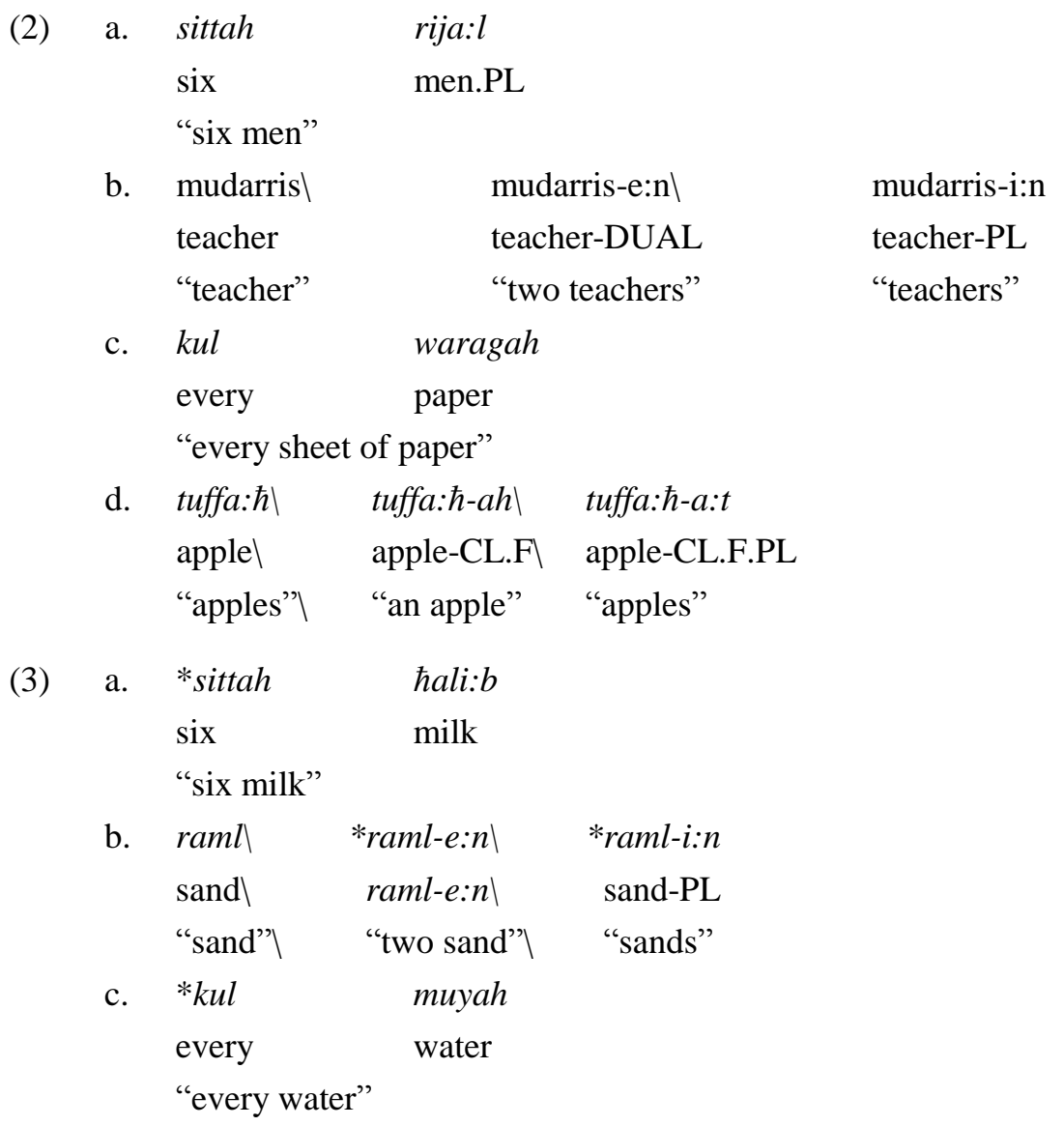




$$
\begin{aligned}
& \text { d. }\left|a s^{\complement} i: r\right| * \text { Kas }{ }^{\varsigma} i: r-a h \\
& \text { juicel juice-CL.F } \\
& \text { "juice" "a juice" }
\end{aligned}
$$

All nouns in (2) are countable. In (2a), the noun rija:l "men" is modified by the numeral sittah "six". The noun mudarris "teacher", in (2b), accepts the number morphology and can be dual or plural. In (2c), the noun waragah "paper" is preceded by the count quantifier kul "every". The noun tuffa: $\hbar$ "apples", in (2d), is a kind noun, therefore, in order to distinguish one apple and many, the classifier - $a h$ or - $a: t$ is added to the word (e.g., tuffa: $\hbar$-ah "one apple" or tuffa: $\hbar$-a:t "apples").

In contrast to the count nouns in (2), all the nouns in (3) are mass nouns. In (3a), the noun $\hbar a l i: b$ "milk" is uncountable and cannot be preceded by a numeral. If a numeral were used in this context, the meaning would be something like "six cartons of milk". The noun raml "sand", in (3b), does not appear in the dual or plural form. In (3c), the noun muyah "water" is a mass noun and cannot be preceded by a count quantifier such as kul "every". Finally, in (3d), no covert/overt classifier can be associated with Sas ${ }^{\text {s }}$ :r "juice".

Nouns have also been classified on a semantic basis (cf. Chierchia, 1985; 1998; Partee, 1986; Jackendoff, 1991; Fassi Fehri, 2005a; 2005b). In this paper, following Jackendoff (1991) and Fassi Fehri (2005a; 2005b), I assume that nouns fall into four distinct classes: (i) individuals, (ii) kinds, (iii) groups, and (iv) masses. Further distinctions within these classes are made according to the binary feature system proposed by Jackendoff (1991) using the features $[ \pm$ Bounded] and $[ \pm$ Internal Structure]. The feature $[ \pm$ Bounded] refers to objects either have or do not have a boundary and the feature [ \pm Internal Structure] refers to entities that comprise a multiplicity of individuals. These formal features are located at D. The different noun classes and features, and their combinations, are set out in Table 1 which graphically illustrates how the feature system works. Thus, individuals have a boundary and lack internal structure, making them undividable into multiple individuals. On the other hand, kinds are unbounded and can be divided into multiple distinct individuals. Groups have both features [+Bounded], [+Internal Structure], thus they are bounded and yet they consist of individuals. Finally, masses lack both features. They are unbounded and cannot be conceived as having multiple distinguishable individuals.

Table 1

Classificatory Featural System for Noun Classes

\begin{tabular}{ccccc}
\hline & Individuals & Kinds & Groups & Masses \\
\hline Bounded & + & - & + & - \\
Internal Structure & - & + & + & - \\
\hline
\end{tabular}

Examples of each of the four noun classes in HA are set out in (4): individuals (4a), kinds (4b), groups $(4 \mathrm{c})$, and masses (4d).
a. $\quad \check{s} u f-t$
al-muddaris
saw-1.SG
the-teacher

"I saw the teacher."
b. Pištare:- $t \quad$ tuffa: $\hbar$
bought-1.SG apple
"I bought apples."




$$
\begin{aligned}
& \text { c. ga:bal-t al-lajnah } \\
& \text { met-1.SG the-committee } \\
& \text { "I met the committee." } \\
& \text { d. Pištare:-t muyah } \\
& \text { bought-1.SG water } \\
& \text { "I bought water." }
\end{aligned}
$$

Individual nouns, as in (4a), are grammatically and semantically singular. All individual nouns are singular and trigger singular agreement. Semantically, they are conceived as a single entity. Such nouns can be pluralized and carry the plural morphology. ${ }^{1}$ Consequently, they can allow numeral modifiers. When pluralized, individual nouns refer to multiple entities. Examples of pluralization and numeral modification are given in (5):
a. al-mudarris ja:
the-teacher came.3.M.SG
"The teacher came."

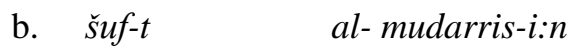
saw-1.SG the-teacher-PL
"I saw the teachers."
c. šuf-t sittah mudarris-i:n
saw-1.SG six teacher-PL

"I saw six teachers."

In (5a), the individual noun mudarris "teacher" is singular and the verb agrees with it in gender and number. The same noun, in (5b), is plural via the addition of the plural suffix $-i: n$. If the noun is plural, it can accept numeral modification as in $(5 \mathrm{c})$.

Kind nouns, illustrated in (6), are grammatically singular yet they are semantically undetermined. They trigger singular agreement, as in (6a). Unlike individual nouns, kind nouns do not refer to multiple individuals when pluralized. Instead, they refer to a large amount or a lot of that kind or different types of that kind, as in (6b). To refer to a single entity of that kind (i.e., an individual member), the unit classifier suffix, -ah, is added

\begin{tabular}{|c|c|c|c|}
\hline 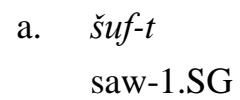 & $\begin{array}{l}\text { bagar } \\
\text { cows }\end{array}$ & $\begin{array}{l}y i-m s ̌ i \\
\text { 3.IMPERF-walk }\end{array}$ & $\begin{array}{l}f i \\
\text { in }\end{array}$ \\
\hline
\end{tabular}
to that noun, as in $(6 \mathrm{c}){ }^{2}$ The new derived noun with the unit classifier can be pluralized and it refers to multiple individuals of that kind, as in (6d). ${ }^{3}$ Notice how these morphosyntactic operations cause the noun to change semantic class which in DM terms would be captured at Vocabulary Insertion (VI). ${ }^{4}$ Thus, the formal features in D combined with the choice of root determine which classifier suffix is inserted.

"I saw cows walking in the field."

\footnotetext{
1 That is, they can carry dual and plural markers.

2 In Arabic, the unit classifier - $a$ h is added to some kind and mass nouns to indicate a unit reading. According to Fassi Fehri (2012), the unit classifier - $a$ h is for non-human nouns. For human nouns, the suffix $-i$ : is used, e.g., Arab/Arab-i: "Arabs/an Arab".

3 The unit classifiers $-a h$ and $-a: t$ in such cases have two functions as a classifier and feminine gender marker.

${ }^{4} \mathrm{VI}$ is the phonological component that is responsible for providing the formal feature morphemes with their phonological representation.
} 


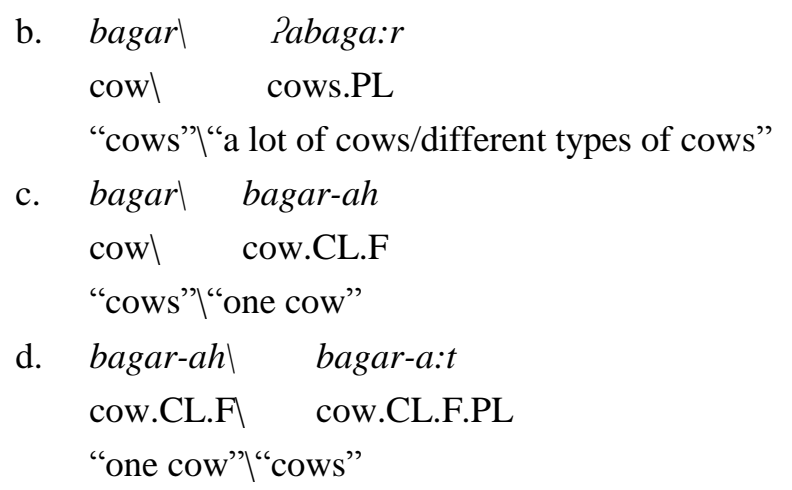

As shown in (7a), kind nouns do not accept numeral modification directly. Instead, the preposition min "of" must come between the numeral and the kind noun to indicate a partitive reading, as in (7b). However, plural nouns derived via the unit classifier - a:t accept numeral modification directly, as in (7c).
a. * २̃štare:- $t$ sittah bagar
bought-1.SG six cow
"I bought six cows."
b. Paštare: $t$ sittah min al-bagar
bought-1.SG six of the-cow
"I bought six cows."
c. Paštare:- $t$ sittah bagar-a:t
bought-1.SG six cow-CL.PL
"I bought six cows."

Group nouns are grammatically singular but semantically plural. A group noun refers to a number of entities. For example, the noun lajnah "committee" refers to a number of people. A single member of this group cannot be called lajnah "committee". Unlike kind nouns, no derived noun can be obtained from the group noun to refer to single entities. Group nouns trigger both singular and plural agreement depending on the speaker's intention. If the speaker wishes to refer to the group as a whole, singular agreement is triggered, as in (8a). On the other hand, if he wishes to refer to each member of the group, then there is plural agreement, as in (8b). A group noun can be pluralized. In such case, it refers to a collection of that particular group, as in (8c). Plural group nouns allow direct numeral modification, as in (8d).
(8)
a. al-lajnah ja:- $t$
the-committee.F came-SG.F
"The committee came."
b. al-lajnah jo:
the-committee came.PL
"The committee came."
c. lajnah $\backslash$ lija:n
"committee"|“committees"
committeel committees.PL 


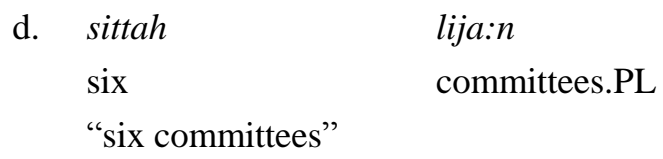

Mass nouns, illustrated in (9), are grammatically singular and semantically uncountable. They trigger singular agreement, (9a). The denotation of a mass noun can be measured but not counted. A classifier or measure phrase is required. The measure phrase, in turn, is countable and can be preceded by a numeral, (9b). If a mass noun is preceded by a numeral directly, a measure reading is conveyed, (9c). Mass nouns cannot be pluralized. If they are pluralized, the noun refers to different types of the mass noun, (9d).

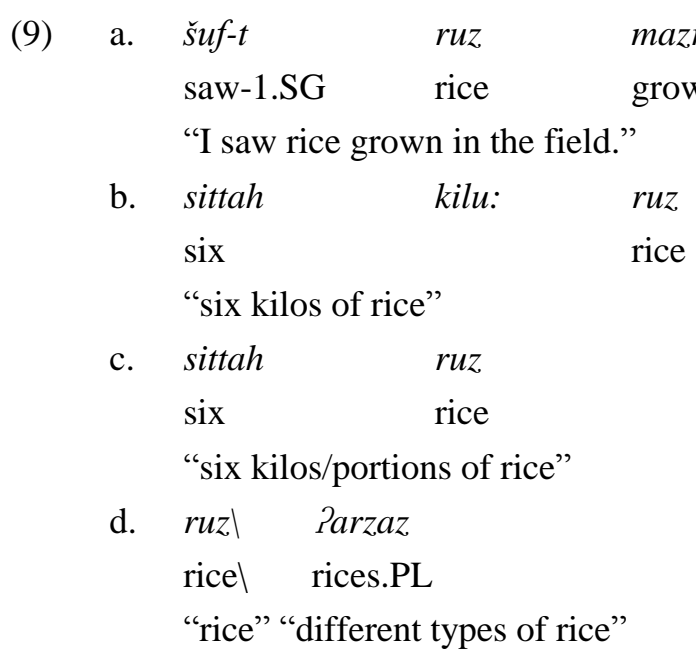

It will be argued in the following section that the features $[ \pm$ Bounded] and $[ \pm$ Internal Structure] are formal features of (n)ominaliser and that they affect the late insertion of the Vocabulary Items competing for (n)ominaliser and Num.

\section{Functional Heads}

As stated previously, the DP in HA has four functional heads: n, Gen, Num, and D. Furthermore, from a DM perspective, all words in a given language consist of category-less roots and abstract morphosyntactic features. One of these features is the category-defining feature (i.e., (n)ominaliser, (v)erbaliser etc....) which is hosted in a functional head that c-commands the root (Halle \& Marantz, 1993; 1994; Marantz, 1997; Harley \& Noyer, 1999; 2000; Pfau, 2000; 2009; Siddiqi, 2006; 2009; Embick \& Noyer, 2007; Embick, 2010; Haugen \& Siddiqi, 2013 among many others). In the case of nouns this functional head is $\mathrm{n}$. In this paper, it is argued that gender, number, and definiteness features also occupy separate functional heads, each of which projects an independent head that dominates the nP. These are described in detail next.

\section{(N)ominaliser Phrase}

It was discussed above that, in DM, words consist of neutral roots headed by at least a category-defining head (i.e., (n)ominaliser, (v)erbaliser etc....). Clearly, therefore, all nouns comprise a root that is c-commanded by the functional head (n)ominaliser. In the Lexicalist hypothesis, words come out of the Lexicon with full information about the syntactic, semantic, and phonological properties of that word. However, since DM rejects the idea of the Lexicon holding fully fledged words with formal, semantic, and phonological information, we propose that the (n)ominaliser head is the locus of all semantic features that pertain to the noun, such as 
[ \pm Bounded], [ \pm Internal Structure] and [ \pm Human]. These semantic features are provided by the Narrow Lexicon along with the neutral root and the other formal features.

The semantic features [ \pm Bounded], $[ \pm$ Internal Structure] play a role in classifying a noun into one of the four classes, as discussed above. As a result, each class deals differently with gender and number features and affects how these features are realized at Spell-Out. Humanness, on the other hand, affects how the number feature $[+\mathrm{PL}]$ is realized (as illustrated later).

The structure of the noun in respect with the category-defining feature and the semantic features is illustrated in (10).

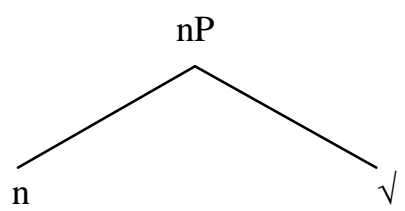

$[\mathrm{n}],[ \pm \mathrm{B}],[ \pm \mathrm{I}],[ \pm$ Human $]$

The Narrow Lexicon provides the syntax with the neutral root, the defining category, and the semantic features. The root merges with the functional head (n)ominaliser which hosts the category-defining feature and the semantic features. At Spell-Out, only the root and the category-defining feature are fleshed out. Consider the following example:

(11) a. kita:b

$$
\text { "book" }
$$

b.

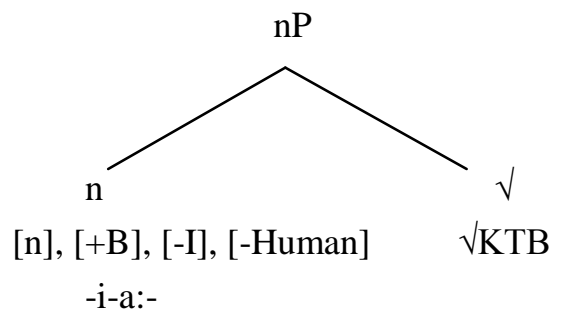

In (11), the noun kita:b "book" belongs to the individual class. It is bounded and has no internal structure. The derivation of this noun begins with the root merging with the functional head (n)ominaliser where the category-defining feature and the semantic features are located. However, at the Vocabulary Insertion stage, only the root and the category-defining feature get Vocabulary Items. The root is fleshed out as $\sqrt{K T B}$ whereas the category-defining feature is fleshed out as the vocalic template in which the root is fitted.

In the case of nouns, the vocalic template realizes only the category-defining feature (n), unless the category-defining feature is fused with another morphosyntactic feature such as number in broken plural nouns, then it realizes both features. For example, the vocalic templat (- i - a: -) in kita:b "book" represents the Vocabulary Item inserted for the category defining feature (n) whereas the vocalic template $(-\mathrm{u}-\mathrm{u}-)$ in kutub "books" represents the Vocabulary Item inserted for the fused features ( $\mathrm{n}$ and number).

The vocalic template itself has no lexical meaning. Sometimes, the same template is used in both nouns and verbs. For example, the vocalic template (- a - a -) can be found in both a noun, e.g., galam "pen", and a verb, e.g., katab "(he) wrote". What distinguishes one category form the other is the word position in the sentence. It is more like the word book in English which can be used as a verb or a noun (both have the same 
form).

Vocalic templates (Vocabulary Items inserted at the Phonological Form (PF) do compete against each other in the same way Vocabulary Items realizing roots or the number feature, for example, compete with each other. The number of Vocabulary Items can be limited to a certain set, as in the number feature case (cf. the Number Section below), or it can be open as in the case of roots. In the same vein, the number of Vocabulary Items realizing the category-defining feature can be open, as in the case of general noun, or it can be limited to some extent to a certain set, as in the case of verbal nouns or verbs. These different combinations of the semantic features, residing in $\mathrm{n}$, affect the derivation and form of the noun. They also force the late insertion of the Vocabulary Items. Consider examples $(6 \mathrm{~b} \& \mathrm{~d})$ repeated here as $(12 \mathrm{a} \& \mathrm{~b})$.

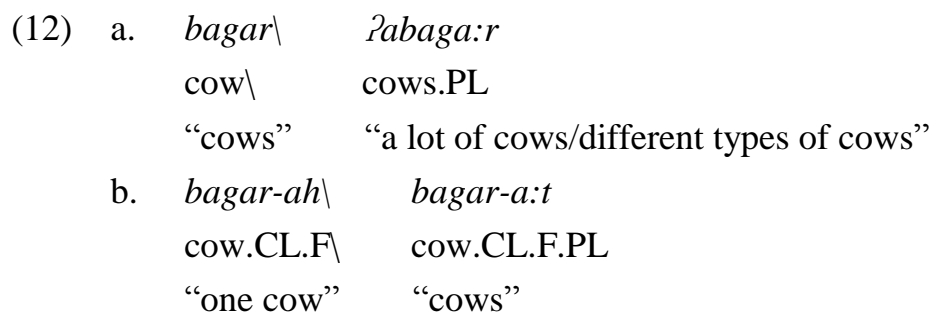

The noun bagar "cows" in (12a) is a kind noun which carries the feature $[-\mathrm{B}]$ and $[+\mathrm{I}]$, so the plural form of it is Pabaga:r "a lot of cows/different types of cows" whereas the noun bagar-ah "one cow" is an individual noun carrying the features [+B], [-I] (due to the classifier) and the plural form is bagar-a:t "cows". Because of the different semantic features of the head $\mathrm{n}$, the Vocabulary Items inserted for the number feature are different. Thus, late insertion guarantees that each feature gets the right Vocabulary Item. If early insertion of the Vocabulary Items is allowed, we would not be able to account for the different singular/plural nouns in (12).

\section{Gender Phrase}

Gender in HA is complicated. There are two gender categories: masculine and feminine. This distinction is semantically arbitrary except for humans. In the case of other animate creatures, a single noun generally refers to either sex of a species (kind noun), for example $d u b$ "bear". Thus, to distinguish males and females, the adjectives Jakar "male" or PunӨa: "female" must be used after the noun. In a few cases, however, there are nouns that are gender specific, for example, Pasad "lion" vs. labwah "lioness", or there are those nouns which are derived from the masculine term via the feminine marker, for example, bis "male cat" vs. bis-ah "female cat".

Masculine is the default form. Thus, masculine nouns are never marked, as can be seen in (13). Feminine nouns, on the other hand, are usually marked with the suffix: $-a$ h or -a:, illustrated in (14). However, there are few nouns that are feminine but which do not carry the feminine marker, as shown in (15). ${ }^{5}$ Consider:

$\begin{array}{lll}\text { rijjal } & \text { galam } & \text { bant }{ }^{\S} \text { alo:n } \\ \text { man } & \text { pen } & \text { pant } \\ \text { "man" } & \text { "pen" } & \text { "pants" } \\ \text { wajb-ah } & \text { sam-a: } & \text { duny-a: } \\ \text { meal-F } & \text { sky-F } & \text { world-F } \\ \text { "meal" } & \text { "sky" } & \text { "world" }\end{array}$

\footnotetext{
${ }^{5}$ In MSA, there are three feminine suffixes: $-a h,-a$ : and $-a$ : ? The glottal stop in the suffix $-a$ : ? is dropped in HA making the last two suffixes the same, e.g., sama: ? "sky" becomes sama: and $s^{5} a \hbar r a: ?$ "desert" becomes $s^{5} a \hbar r a:$ :
} 


$\begin{array}{lll}\text { umm } & \text { gadam } & \text { yad } \\ \text { mother.F } & \text { foot.F } & \text { hand.F } \\ \text { "mother" } & \text { "foot" } & \text { "hand" }\end{array}$

In (13), all three nouns are masculine and are morphologically unmarked. On the other hand, all three nouns in (14) are feminine. The first carries the feminine marker -ah. However, there is no such noun as wajb without the feminine marker. Similarly, the last two nouns carry the other feminine marker - $a$ : and, again, there are no masculine counterparts of these feminine nouns. ${ }^{6}$ Finally, while all three nouns in (15) are feminine, they are not marked with a feminine marker. However, if they are modified by an adjective, the adjective must carry a feminine marker. Consider example (16):

$$
\begin{array}{ll}
\text { gadam } & \text { kabi:r-ah } \\
\text { foot.F } & \text { big-F } \\
\text { "a big foot" } &
\end{array}
$$

Of the four noun classes in HA, individuals, groups, and masses can be masculine or feminine whereas the fourth class, kinds, is always masculine. As mentioned above, the classifier suffix - $a$ h can be added to non-human kind nouns to refer to individual(s). ${ }^{7}$

The most common and also productive feminine suffix is $-a h$. As shown in the examples in $(17 \mathrm{a} \& \mathrm{~b})$, it is used to derive the feminine forms out of masculine nouns which refer to humans, (17a), and living creatures, (17b). Furthermore, kind nouns are always masculine. The unit classifier - $a$, which specifies a single unit of kind nouns, renders the noun feminine, $(17 \mathrm{c})$.

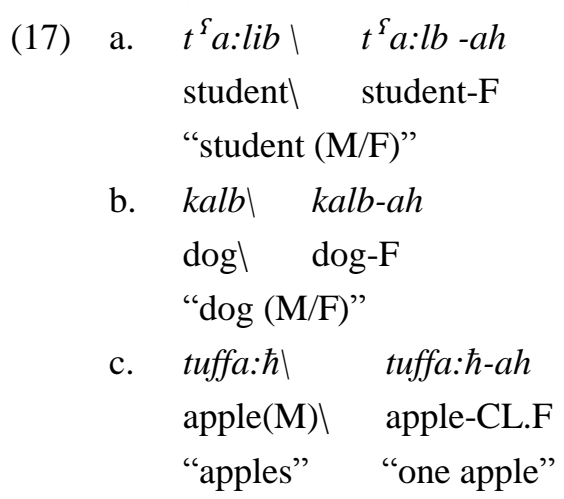

\begin{tabular}{|c|c|c|c|c|c|c|}
\hline \multirow[t]{2}{*}{ (18) $\mathrm{a}$} & 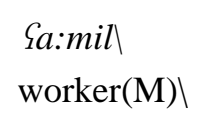 & $\begin{array}{l}\text { Summa:l } \\
\text { workers.PL(M) }\end{array}$ & 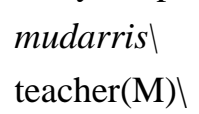 & $\begin{array}{l}\text { mudarris- } i \text { : } \\
\text { teacher-PL(M) }\end{array}$ & 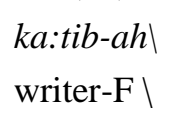 & $\begin{array}{l}\text { ka:tib-a:t } \\
\text { writer-F.PL }\end{array}$ \\
\hline & "worker/s" & & "teacher/s" & & "female w & ter/s" \\
\hline \multirow[t]{3}{*}{ (19) } & kita:b\} $&{\text { kutub }} &{\text { galam\ }} &{\text { Pagla:m }} &{w a j b-a h \backslash} &{\text { wajb-a:t }} \\
{\hline} &{\operatorname{book}(\mathrm{M}) \backslash} &{\text { books.F.PL }} &{\operatorname{pen}(M) \backslash} &{\text { pen.F.PL }} &{\text { meal-F }} &{\text { meal-F.PL }} \\
{\hline} &{\text { "book/s" }} &{ } &{\text { "pen/s" }} &{ } &{\text { "meal/s" }} &{ } \\
$\hline
\end{tabular}

Human nouns have the same gender whether they are singular or plural. However, non-human nouns, masculine, and feminine, become feminine when they are pluralized,, as illustrated in (18) and (19).

In (18), all three nouns refer to human beings and each preserves the same gender in its plural form as it has in its singular form regardless of the type of plural it takes (broken, sound masculine or sound feminine

\footnotetext{
${ }^{6}$ Roots usually consist of consonants. However, in some cases the semi vowels /w/ and /y/ can be part of the root, as in the examples above.

${ }^{7}$ Recall that the classifier - $a h$ is also the feminine marker.
} 
respectively). ${ }^{8}$ On the other hand, the non-human nouns, illustrated in (19), are grammatically feminine in their plural form even though the first two are masculine when singular.

Furthermore, non-human plural nouns (both broken and sound feminine forms) are treated as feminine singular nouns in the sense that they trigger feminine singular agreement on verbs and modifiers, as in (20). In addition, human feminine plural nouns which refer to humans trigger masculine plural agreement on verbs and modifiers, as in (21).

$\begin{array}{lll}\text { al-kutub al-mufi:d-ah } & \text { wi } s^{\varsigma} l \text {-at } \\ \text { the-books.F.PL } \quad \text { the-useful-F(SG) } & \text { arrived-F(SG) } \\ \text { "The useful books have arrived." } & \\ \text { al-t } t^{\varsigma} \text { a:lb-a:t al-hilw-i:n } & \text { wi } s^{\varsigma} l-u: \\ \text { the-student-F.PL the-beautiful-PL } & \text { arrived.-PL } \\ \text { "The beautiful female students arrived." } & \end{array}$

In (20), kutub "books" is the feminine plural form of the masculine singular noun kita:b "book". Yet, both the adjective and the verb carry feminine singular agreement. On the other hand, in (21), $t^{\text {f }} a: l b$-a:t "female students" is feminine plural and the agreement it triggers on the adjective and the verb is (masculine) plural.

From a DM perspective, it is proposed that in both cases Impoverishment is involved. In agreement involving non-human plural nouns, the number feature $[+\mathrm{PL}]$ is deleted resulting in the occurrence of the default form of the number feature (singular) at Spell-Out which is unmarked. Similarly, the gender feature [F] is deleted in human feminine plural nouns leaving the gender feature in its default form (masculine) which also unmarked. Both Impoverishment rules are expressed in (22) and (23) respectively.

Impoverishment rule for agreement with non-human non-singular nouns

$$
[+\mathrm{PL}] \rightarrow \varnothing / \_[-H u m a n]
$$

Impoverishment rule for agreement with human feminine non-singular nouns

$$
[\mathrm{F}] \rightarrow \varnothing / \ldots[+\mathrm{PL}],[+ \text { Human }]
$$

To summarize, it has been argued so far that singular is the default number and only plural is marked and also that masculine is the default gender and only feminine is marked. In terms of agreement, it seems that no two marked values can co-occur. Thus, in non-human feminine plural nouns, the agreement is feminine and singular whereas in human feminine plural nouns, agreement is masculine and plural. ${ }^{9}$

It remains to consider the question whether (Gen)der projects an independent head in HA. To illustrate the problem, in the case of Catalan, for example, Picallo (1991) argues that all nominals belong to a particular gender which may have semantic content. This gender is expressed overtly on the determiner and triggers agreement on the modifying adjective. Therefore, he proposes that gender projects into a syntactic functional

\footnotetext{
${ }^{8}$ Sound vs. broken plural refers to the formal relationship between the plural noun form and the corresponding singular form. In a sound plural, the plural marker is a suffix hosted by a stem phonologically identical to the singular form, whereas in a broken plural the root of the singular noun is fused with the plural marker; that is the root is mapped onto a different template than it is in the singular form (cf. the Number Section below)

${ }^{9}$ In MSA, human feminine plural nouns trigger feminine plural agreement. In HA, you may hear a human feminine plural noun that is modified by a feminine plural adjective (only adjectives). I argue that this is a matter of diglossia and dialect switching. What is interesting here is that feminine agreement is not also on the verb. One can imagine a grammar where nouns and adjectives agree, i.e., have the same form, whereas agreement on verbs differs (a very common phenomenon).

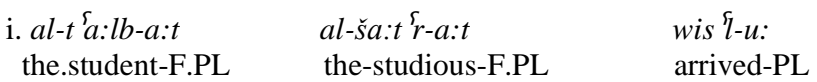

"The studious female students arrived." 
category, GenP, in all Catalan nominals. In the same vein, Bernstein (1993) argues that GenP (she uses the term Word Marker Phrase (WMP)) is not universal but that it projects its functional head in languages with $\mathrm{N}$ stems containing a word-marker that refers to gender (e.g., Spanish and Italian). She adds that N moves to Num via Gen.

On the other hand, linguists such as Ritter (1993) and Kremers (2003) reject the idea of a separate GenP. Ritter claims that there is no distinct GenP in Hebrew; rather it is a feature either on $\mathrm{N}$ or on Num depending on the language ( $\mathrm{N}$ for Hebrew, Num for the Romance languages). For example, the noun šana "year" is feminine and triggers feminine agreement on a modifying adjective. The plural form šan-im "years" is also feminine even though it takes the masculine plural marker -im because it also triggers feminine agreement on the adjective. Consider these examples given by Ritter (1993, p. 799):

\begin{tabular}{lll|ll} 
a. & šana & tov- $a$ & *šana & tov \\
& year(F) & good-F & year(F) & good-F \\
b. & $\check{\text { san-im }}$ & tov-ot & šan-im & tov-im \\
& year(F)-PL & good-F.PL & year(F)-PL & good-M.PL
\end{tabular}

Kremers (2003) agrees with Ritter's (1993) proposal. He argues that the plural markers -u:na and -a:t in MSA serve as number markers and at the same time indicate gender. $\mathrm{He}$ analyses these two markers as syncretic heads where the presence of either feature, gender, or number, implies the other. ${ }^{10}$ He notes further that in the singular and broken plural, masculine gender is never marked explicitly; this means [Gen: M] never projects a Gen head. Furthermore, the feminine marker -ah, which comes with singular feminine nouns, is a syncretic head signaling the features [Gen: F] and [Num: -PL]. Therefore, Gen itself is never a separate head but instead is present either on the noun stem or the Num head. Kremers discusses GEN with sound masculine and feminine plurals and claims that the number markers can indicate the gender of the noun. Nevertheless, he says nothing about the broken plural which has no suffix marker and can be either masculine or feminine. In addition, he is not consistent when proposing different treatments for the masculine singular and feminine singular nouns. He suggests that masculine singular nouns do not project a GEN head at all, whereas feminine singular nouns have a syncretic head that indicates both GEN and Num. However, he says nothing about feminine singular nouns with no feminine marker, such as Pumm "mother".

The fusion of the gender and number features as described in the above cases might be the reason Ritter (1991) and Kremer (2003) both propose a syncretic head that combines both gender and number features. However, there are instances where these features are given separate Vocabulary Items at Spell-Out. Consider the following examples:

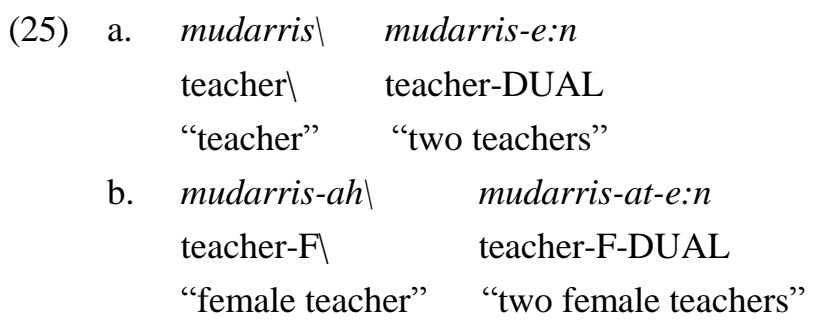

\footnotetext{
${ }^{10}$ A syncretic head is a hybrid head, i.e., two different heads are expressed as one element, e.g., English Agr/T head. In DM, this phenomenon is considered an instance of fusion.
} 
In (25a), the noun mudarris "teacher" is a singular and masculine noun to which the dual suffix marker is attached to yield the dual form. On the other hand, in (25b), the noun mudarris-ah "female teacher" is a feminine singular noun with a feminine marker. To obtain the dual form, the dual suffix is attached after the feminine marker with no fusion between the two heads.

In DM, it is assumed that roots have no active formal syntactic features (Halle \& Marantz, 1993; Harley \& Noyer, 1999; Embick \& Noyer, 2007; Siddiqi, 2009; Haugen \& Siddiqi, 2013 among many others). Thus, it is argued that the derivation of nouns in HA includes a separate Gen head which can be either masculine or feminine. This way, we can account for the gender feature realization at Spell-Out especially in the case of the productive feminine marker $-a h$ which derives feminine nouns from masculine ones and in the case of example (25b) where there are three Vocabulary Items representing the root, gender feature, and number feature. A single Vocabulary Item in DM can only be inserted in a single terminal node. If we supposed that the gender feature is subsumed under (n)ominaliser or Num, we would not be able to provide it with a separate Vocabulary Item as in (25b). The root, $\sqrt{ }$, merges with (n)ominaliser which projects nP. nP subsequently merges with Gen, as illustrated in (26). At the Vocabulary Insertion component, all terminal nodes (root, nominaliser, and Gen) are fleshed out.

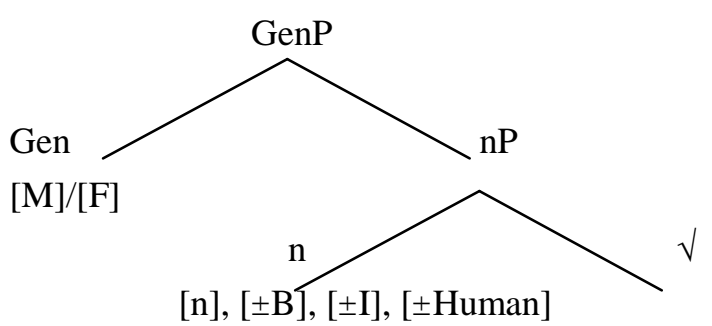

Feminine gender is derived in two different ways in HA. First, there is the feminine suffix $-a h$ which is used productively to change the gender of human and non-human nouns from masculine to feminine; that is the feminine marker is detachable and is added to the noun stem to yield the feminine form, for example, muddaris "teacher" becomes muddaris-ah "female teacher". In this case, the feminine feature is directly fleshed out as $-a h$ at Vocabulary Insertion, as in (27). In an alternative derivational process the feminine morphology is not detachable from the stem. This happens when the noun has no masculine counterpart from the same root and the feminine suffix is part of the noun, as in wajbah "meal" or dunya: "world", or when the feminine noun does not carry a feminine marker such as gadam "foot", as in (28). In this case, it is argued that the Gen head and the (n)ominaliser are fused at the morphology and given one Vocabulary Item at Spell-Out. The fusion rule in (29) states that whenever the noun is feminine and has no masculine counterpart of the same form, both (n)ominaliser and Gen are fused. Thus, the fused terminal node is given one Vocabulary Item at Spell out. The Greek small letter koppa (ל) is used to indicate that the noun has no masculine counterpart of the same form.

(27) a. muddaris-ah

teacher-F

"female teacher" 
b.

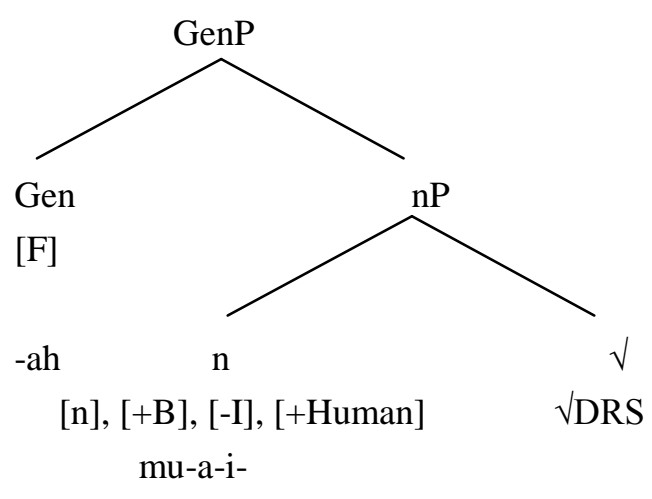

(28)
a. wajb-ah duny-a: gadam
meal-F world-F foot.F
"meal" "world" "foot"

b.

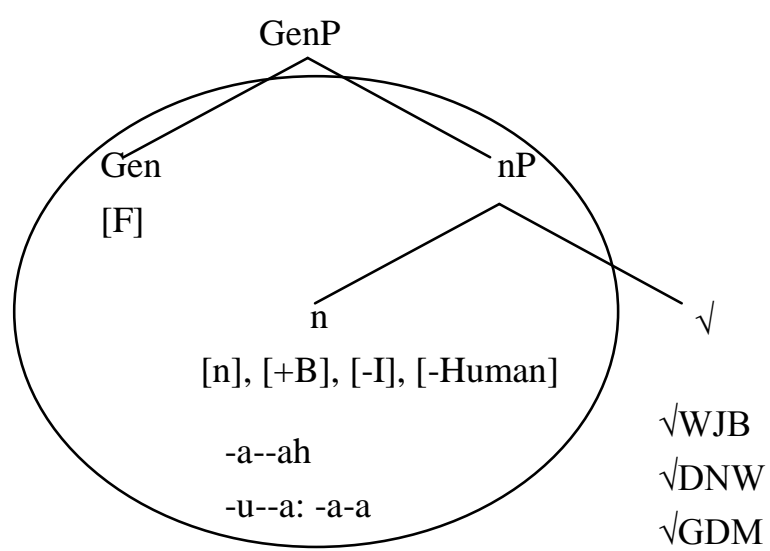

Fusion rule for (n)ominaliser and feminine gender:

$$
[\mathrm{n}]+[\mathrm{Gen}] \rightarrow[\mathrm{n}, \mathrm{Gen}] /[\text { _ }[\mathrm{Gen}: \zeta \mathrm{F}]
$$

In (27a), a masculine noun is changed into feminine by the addition of the feminine marker $-a h$. Thus, at Spell-Out, the root, n, and Gen are given separate Vocabulary Items. On the other hand, in (28a), all three nouns are feminine and they have no masculine counterparts from the same root, therefore, the feminine markers in the first two of them (wajbah and dunya:) are not detachable. They are part of the pattern in which the root is fitted. Therefore, in all three words, the (n)ominaliser and Gen are fused at the morphology and at Spell-Out they are given one Vocabulary Item.

There are two Vocabulary Items that can compete for insertion for the Gen feature. They are:

$$
\begin{aligned}
& \text { Vocabulary Items for Gen feature } \\
& -\mathrm{ah} \longrightarrow \begin{array}{l}
{[\mathrm{F}]} \\
\varnothing
\end{array} \quad \text { elsewhere }
\end{aligned}
$$

Thus, if Gen feature is $[\mathrm{F}]$ and fused with $\mathrm{n}$, the Vocabulary Item inserted is the feminine marker -ah. As for the other feminine marker $-a$; , it always occurs with feminine nouns that has no masculine counterpart from the same root, as in (28); therefore, in such words Gen fuses with $\mathrm{n}$ and are given on vocabulary item that refers 
to both features.

It was stated earlier in this section that with nouns denoting animate living creatures, there is a generic noun that refers to both sexes of that species and to distinguish the male form the female, an adjective must be used. However, there are few nouns that are gender specific, such as Pasad/labwah "lion/lioness". So, how are these two nouns derived? It is proposed that they are derived like any other noun with a neutral root that merges with (n)ominaliser and then Gen. At Spell-Out, the Vocabulary Item that is inserted for the root is different and depends on the gender feature. If the feature is masculine, then the Vocabulary Item inserted for the root is $\sqrt{ }$ ? $S D$ and the pattern that is inserted in $\mathrm{n}$ is (-a-a-). Since masculine gender is the default value for gender, it is not marked. On the other hand, when the gender feature is feminine, then the Vocabulary Items, inserted for the root, $\mathrm{n}$, and Gen feature, are $\sqrt{ } L B W$ and (-a--ah). Since there is no masculine counterpart from the same root, $\mathrm{n}$ and Gen undergo fusion and are given one Vocabulary Item at Spell-Out.

This example shows how late insertion is important even for roots. The interaction between the root and the formal features, gender in this case, determines the choice of the Vocabulary Items for the root and the vocalic template in $\mathrm{n}$.

\section{Number Phrase}

HA nouns are marked for three different number categories: singular, dual, and plural. Singular is the default form and, grammatically, all four noun classes in HA are singular in their derivation. Dual and plural are extensions of that form in various ways.

Unlike in English, where there is no dual morphology and it is expressed by two or both combining with a count noun to indicate the dual form, dual in HA is formed by attaching a special suffix, $-e: n$, to the base form of the count noun regardless of the noun's gender. ${ }^{11}$ In (31), the same dual number suffix is attached to both masculine and feminine nouns.
a. mudarris
mudarris-e:n
teacherl
teacher-DUAL
"teacher"
"two teachers"
b. mudarris-ah
mudarris-at-e:n
teacher-Fl
teacher-F-DUAL
"female teacher" "two female teachers"

Unlike the dual form, plural is formed in two different ways with either the regular grammatical plural or the irregular broken plural. Grammatical plural is achieved by the addition of a suffix to an invariable stem noun. There are two suffixes and the choice of suffix depends on the gender of the noun. The first, $-a: t$, is usually associated with feminine gender and the second, $-i: n$, is associated with human masculine nouns. These

\footnotetext{
11 HA can use the number PiOne:n "two" with the plural form of the noun as an alternative to noun + dual suffix with indefinite dual nouns, for example: 
plural morphemes are also known as the "sound plural": the sound feminine plural and the sound masculine plural respectively (Ryding, 2005). ${ }^{12}$ The broken plural, on the other hand, is fusional. Plural is marked in this way by fusing the consonantal root of the singular noun with other vowels and sometimes the consonant /R/, e.g., kita:b/kutub "book/books" and nahar/Panha:r "river/s".

The sound feminine plural is very common in HA. It applies mostly to female humans. However, there are cases where it is used to pluralize feminine nouns (both animate and inanimate) and some inanimate masculine nouns. To pluralize any noun from the above mentioned types, - a:t is added to the stem noun. Should the singular noun end with the feminine gender marker - $a$, the sound feminine plural suffix -a:t is substituted, as shown in (32). ${ }^{13}$

\begin{tabular}{|c|c|c|c|c|c|}
\hline $\begin{array}{l}\text { mudarris } \backslash \\
\text { teacher }\end{array}$ & $\begin{array}{l}\text { mudarris-a:t } \\
\text { teacher-F.PL }\end{array}$ & $\begin{array}{l}\text { sayya:r-ah } \\
\text { car-F } \\
\text { "car/s" }\end{array}$ & $\begin{array}{l}\text { sayya:r-a:t } \\
\text { car-F.PL }\end{array}$ & $\begin{array}{l}m a t^{\varsigma} a: r \downarrow \\
\text { airport(M) } \\
\text { "airport/s" }\end{array}$ & $\begin{array}{l}m a t^{\varsigma} a: r-a: t \\
\text { airport-F.PL }\end{array}$ \\
\hline
\end{tabular}

The sound masculine plural is more restricted in its occurrence than that of the sound feminine plural and it is only used on nouns referring to male humans or mixed groups of males and females. ${ }^{14}$ The sound masculine plural is marked by attaching the suffix $-i: n$ to a stem equivalent to the singular noun form. Note that in the following example (33), the feature [ \pm Human] plays a role in the sound masculine plural.

a. mudarris $\backslash$ mudarris-i:n
teacher
"teacher/s"

falla: $\hbar \backslash$ falla: $\hbar-i: n$
farmer farmer-PL
"farmer/s"

The broken plural is widespread in Arabic and it is used mostly for pluralizing non-human nouns. It is expressed via the fusion of vowel patterns in noun consonantal roots. It resembles to some extent ablaut, for example, vowel quality differences distinguish singular and plural in some English words (e.g., "foot/feet", "mouse/mice") instead of the regular plural marker. Sometimes, the broken plural may include insertion of the glottal stop / $/$ / to the template, for example, galam/Ragla:m "pen/s". Over the last 15 years, many studies in morphological theory have been conducted to refine the analysis of the Arabic broken plural system and significant progress has been achieved in developing theories that explain and specify the underlying regularities in the broken plural system. The most outstanding of these are the templatic morphology and prosodic morphology approaches (see McCarthy \& Prince, 1990a; 1990b; Ratcliffe, 1998).

$\begin{array}{clll}\text { (34) bis/bias:s } & \text { rijja:l/rija:l } & \text { mirsam-ah/mara:sim } & \text { nahr/Pnha:r } \\ \text { cat/cats.PL } & \text { man/men.PL } & \text { pencil-F/pencils.PL } & \text { river/rivers.PL } \\ \text { "cat/s" } & \text { "man/men" } & \text { "doubt/s" } & \text { "river/s" }\end{array}$

In (34), four different nouns that refer to human and non-human (animate and inanimate) entities are illustrated. What is common to the singular and plural forms is just the consonantal root which is mapped onto different syllabic templates and different vowel melodies.

Concerning the syntactic representation of (Num)ber, there is consensus between linguists that Num projects its head between DP and NP (Abney, 1987; Picallo, 1991; Ritter, 1992; Kremers, 2003 among many

\footnotetext{
${ }^{12}$ From now on, the terms sound feminine plural and sound masculine plural will be used to distinguish between the two types of the grammatical plural.

13 The /h/sound in the feminine marker /-ah/ changes to /t/ in the construct state structure, e.g., muddaris-ah "female teacher"; muddaris-at al-fas' $l$ "teacher of the class".

${ }^{14}$ There are some exceptions. Some nouns, which refer to masculine human beings, undergo broken plural process, e.g., rijja:l/rija:l "man/men".
} 
others). In this paper, it is argued that all noun classes have a NumP in their derivation since all classes can be pluralized whether the plural refers to multiple individuals (individual nouns), multiple groups (group nouns), or multiple types or kinds (kind and mass nouns).

The structure of the noun with respect to NumP is illustrated in (35). The root merges with (n)ominaliser. The whole nP then merges with Gen where the gender feature is hosted. Finally, GenP is merged with Num where the number feature is located. The number feature can be singular [-PL], dual [+DUAL, +PL], or plural [+PL].

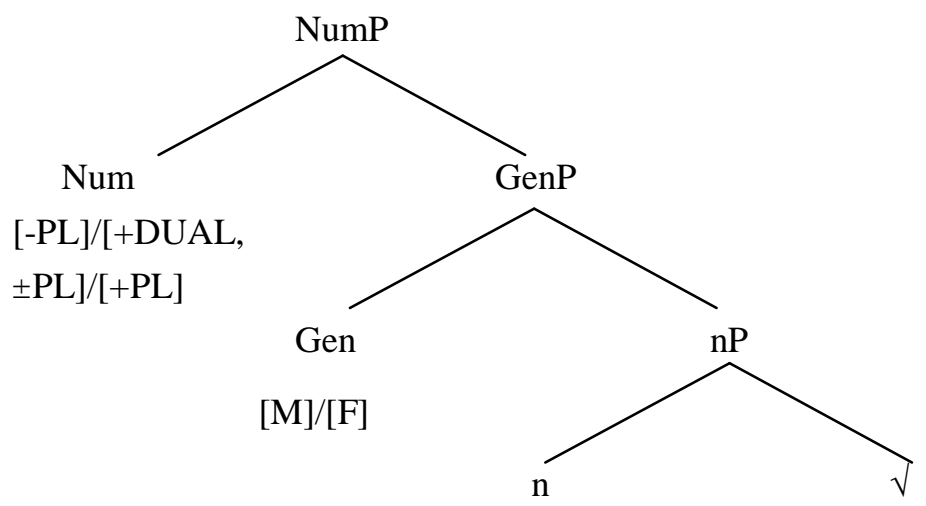

$[\mathrm{n}],[ \pm \mathrm{B}],[ \pm \mathrm{I}],[ \pm$ Human $]$

As described so far in this section, plural in HA can be expressed in one of two ways; there is the grammatical plural where a suffix is attached to the noun stem and there is the broken plural where only the consonantal root of the singular noun is kept and fitted with a vowel pattern into a syllabic template. Having said this, it is proposed that number is incorporated with the noun in one of two different ways: Either there is no fusion between the different features, or there is fusion between Num and Gen features (sound feminine plural) or between Num and $\mathrm{n}$ features (broken plural). The first scenario (i.e., no fusion) applies when deriving a singular noun, as in (36), a dual noun, as in (37), or a sound masculine plural, as in (38).

(36) a. muddaris

teacher

"teacher"

b.

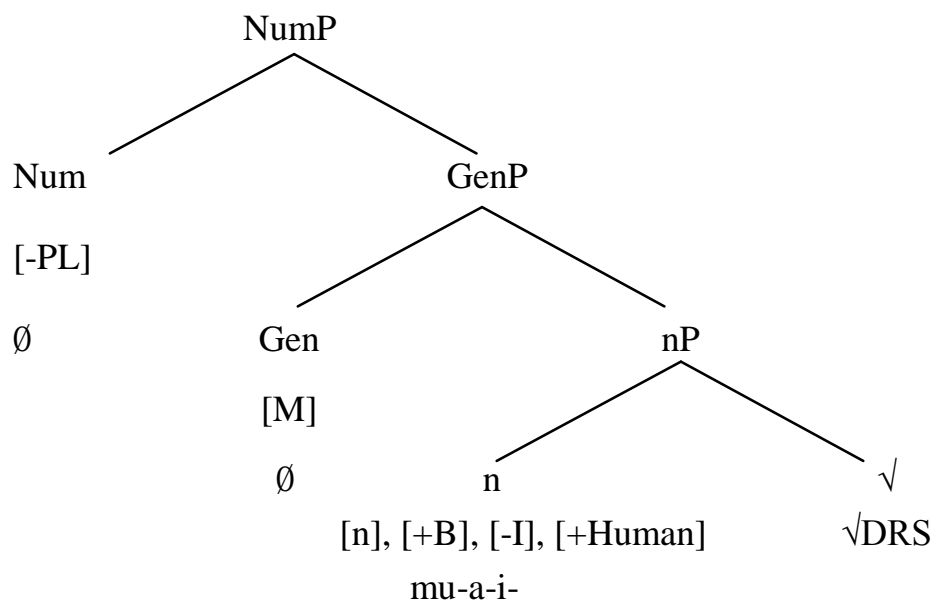


(37) a. muddaris-at-e:n

teacher-F-DUAL

"two female teachers"

b.

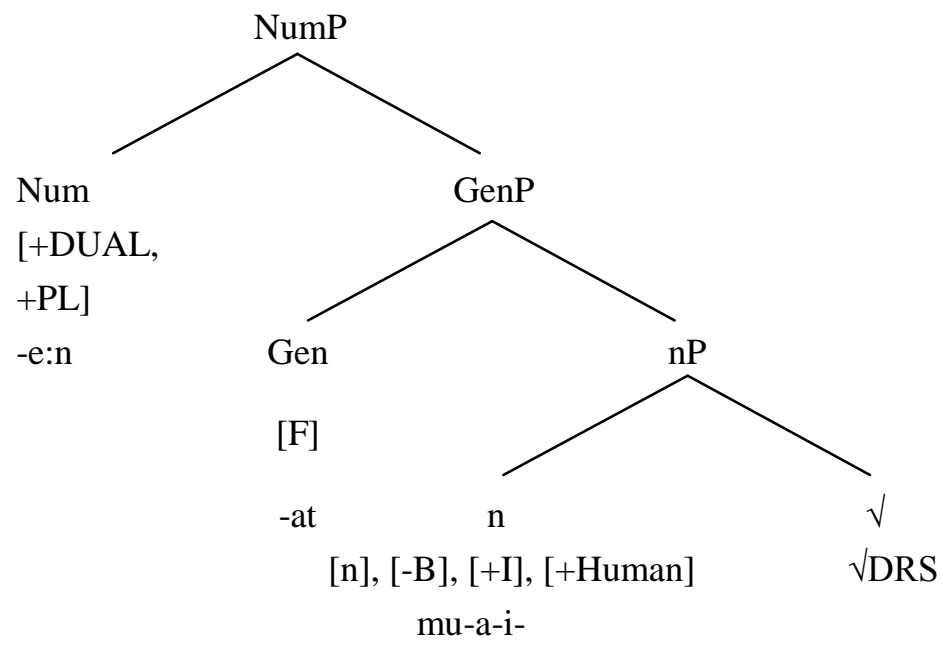

(38) a. muddaris-i:n

teacher-PL

"teachers"

b.

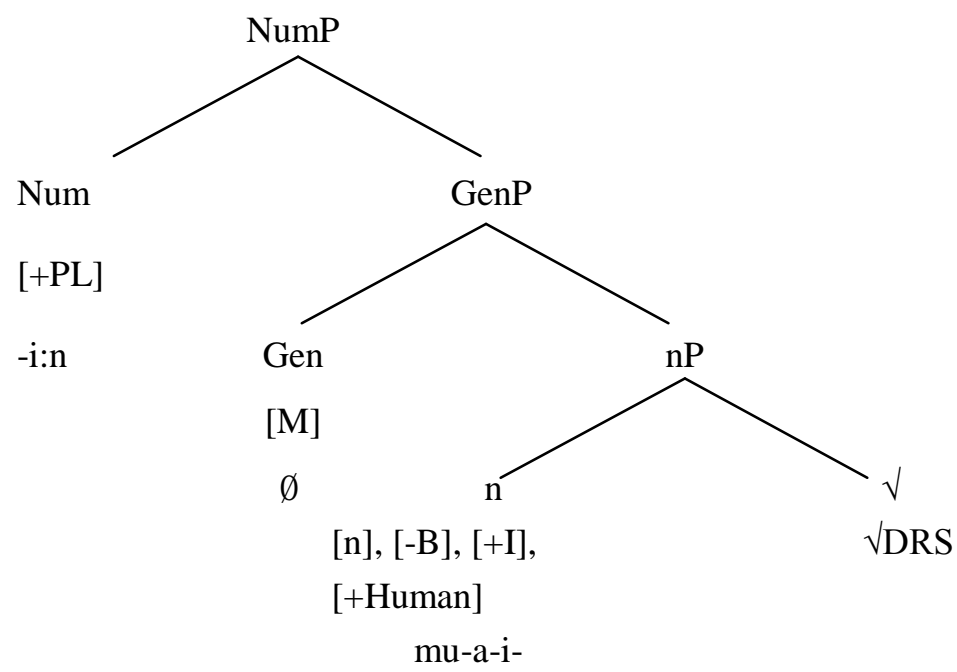

The derivation of the three nouns in (36), (37), and (38) is straightforward. The root merges with $\mathrm{n}$ which in turn merges with Gen and Num. At Spell-Out, each single terminal is given a separate Vocabulary Item, and there is no fusion between the terminals. In the case of masculine gender and singular number, the Vocabulary Item is $\varnothing$ 
There are five Vocabulary Items that can compete for insertion for the Num feature. They are:

$\begin{array}{lll}\begin{array}{l}\text { Vocabulary Items for the Num feature } \\ \text {-a:t }\end{array} & \\ \text { irregular (broken plural) } & & {[+\mathrm{PL}],[\mathrm{F}],[+ \text { Human }]} \\ -\mathrm{e}: \mathrm{n} & \longrightarrow & {[+\mathrm{PL}],[- \text { Human }]} \\ -\mathrm{i}: \mathrm{n} & \longrightarrow & {[+\mathrm{DUAL},+\mathrm{PL}]} \\ \varnothing & \longrightarrow & {[+\mathrm{PL}]} \\ & \longrightarrow & \text { Elsewhere }\end{array}$

(40) a. Competition into Num feature in (36b):

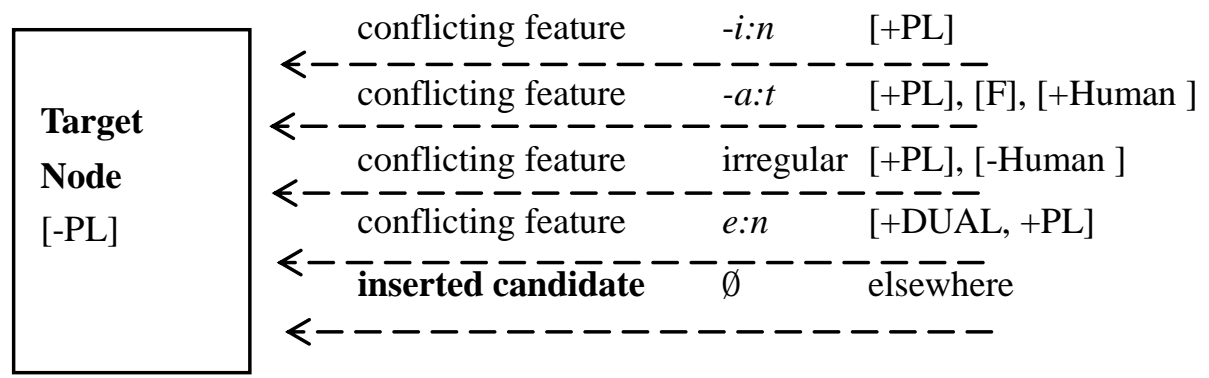

b. Competition into Num feature in (37b):

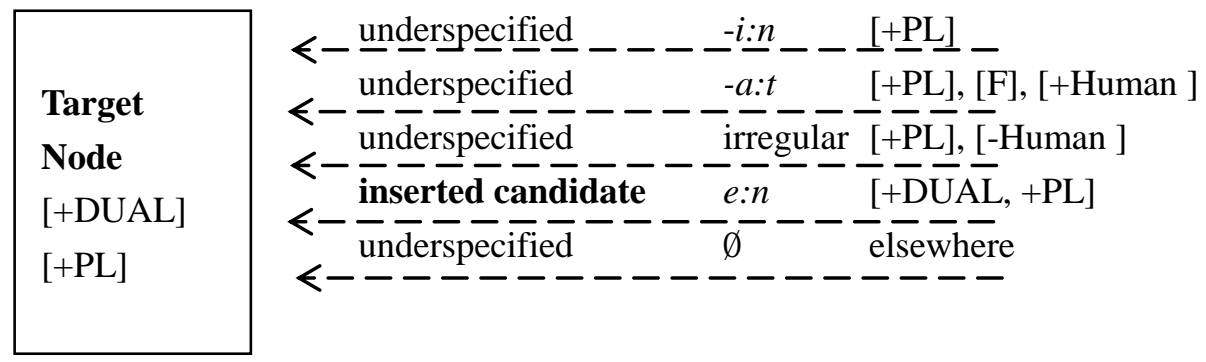

c. Competition into Num feature in (38b):

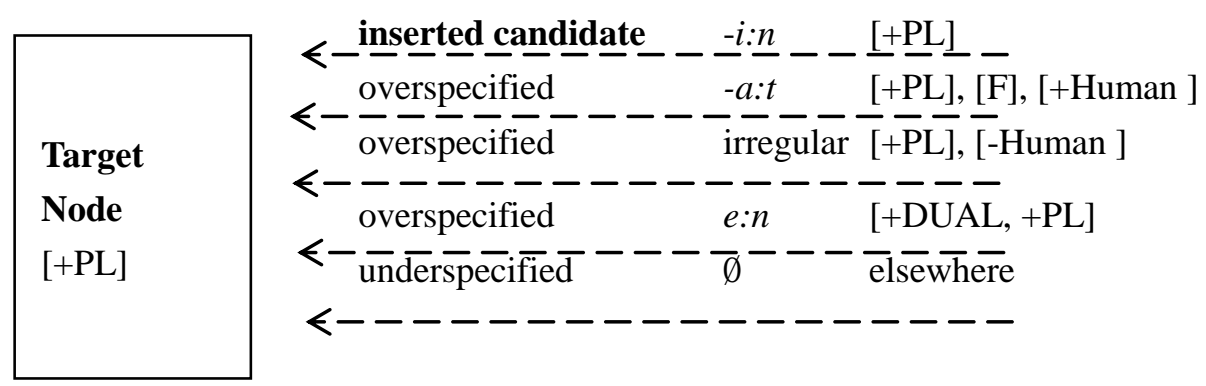

The second scenario (i.e., fusion) occurs when deriving a sound feminine plural noun (Gen and Num), as in (41), or a broken plural noun (n and Num), as in (42). Another morphological process is associated with broken plural in HA. An Impoverishment occurs to the gender feature deleting it and its Vocabulary Item. The fusion rule that applies in each case is expressed in (43) and (44) respectively whereas the Impoverishment rule is expressed in (45).

\footnotetext{
15 Unlike the sound feminine and masculine plural which has one form each, the broken plural is described irregular because it has about 30 different forms; yet, some of those forms are productive.
} 
(41) a. muddaris-a:t

teacher-F.PL

"female teachers"

b.

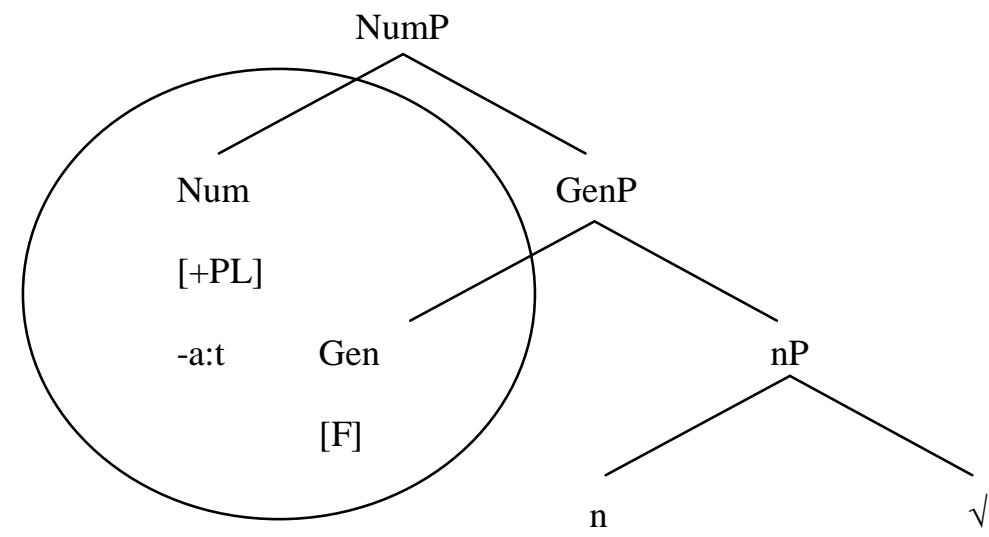

[n], [-B], [+I], [+Human]

$\sqrt{D R S}$

mu-a-i-

(42) a. kutub

books.PL

"book"

b.

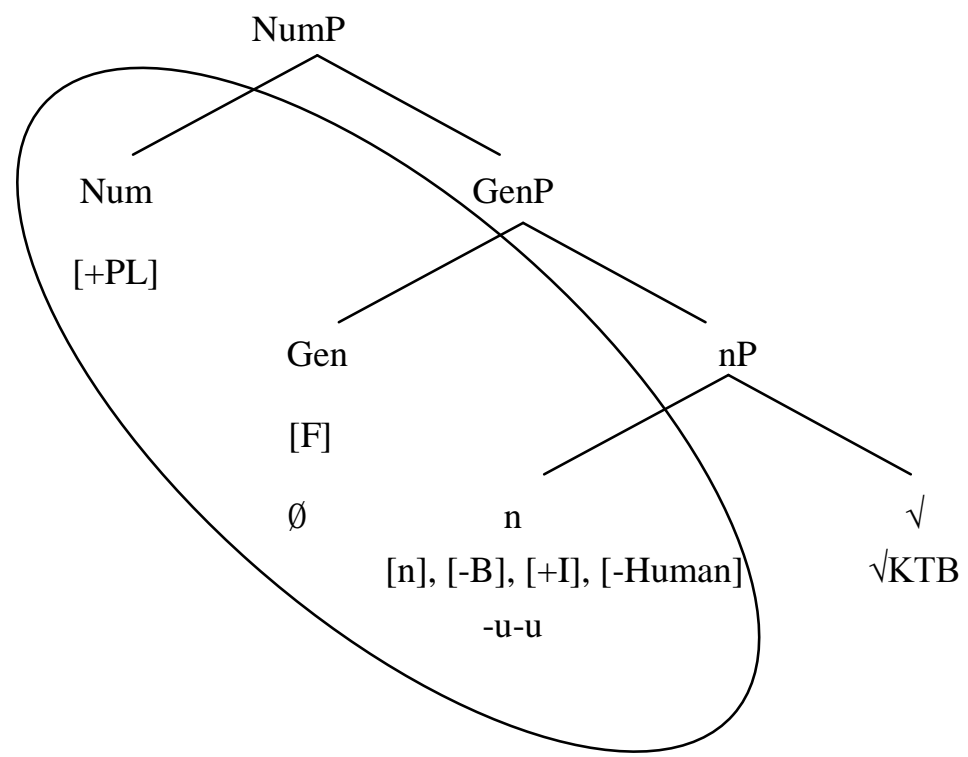

In (41) and (42), the nouns are sound feminine plural and broken plural respectively. In both cases the derivation proceeds in the syntax as described above. However, at the morphology stage a fusion occurs between the Num and Gen features in the sound feminine plural and between the Num and $\mathrm{n}$ features in the 
broken plural. At Spell-Out, the former is given the fused sound feminine plural marker -a:t and the latter is given a plural templatic pattern.

Fusion rule for feminine plural inflection on sound noun

$[\mathrm{Gen}]+[\mathrm{Num}] \rightarrow[$ Gen, Num]/__ $[\mathrm{F}],[+\mathrm{PL}],[+$ Human $]$

Fusion rule for broken plural

$$
[\mathrm{n}]+[\mathrm{Num}] \rightarrow[\mathrm{n}, \mathrm{Num}] /[\ldots[+\mathrm{PL}],[- \text { Human }]
$$

Impoverishment rule for feminine inflection on broken plurals

$[\mathrm{F}] \rightarrow \varnothing / \ldots[+\mathrm{PL}],[-$ Human $]$

The fusion rule in (43) states that both Gen and Num are fused when the noun is $[\mathrm{F}],[+\mathrm{PL}]$, and [+Human]. In this case, a single Vocabulary Item is given to the fused terminal node that expresses both the gender and number features. On the other hand, in (44), the rule states that both (n)ominaliser and Num are fused when the noun is [+PL] and [-Human]. At spell-Out, the newly fused terminal node is fleshed out as one Vocabulary Item. Thus, the vocalic template, which the root is fitted in, expresses both the category-defining feature and the number feature. Rule (45) describe the Impoverishment process that occurs to broken plural nouns. The gender feature is deleted and so is the Vocabulary Item that should represent it at Spell-Out.

(46) a. Competition into Num feature in (41b):

\begin{tabular}{|c|c|}
\hline $\begin{array}{l}\text { Target } \\
\text { Node } \\
{[+\mathrm{PL}]} \\
{[\mathrm{F}]} \\
\text { [+Human] }\end{array}$ & 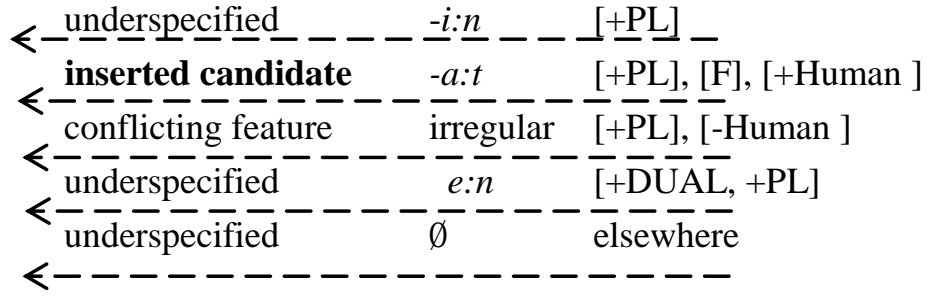 \\
\hline
\end{tabular}

b. Competition into Num feature in $(42 b)$ :

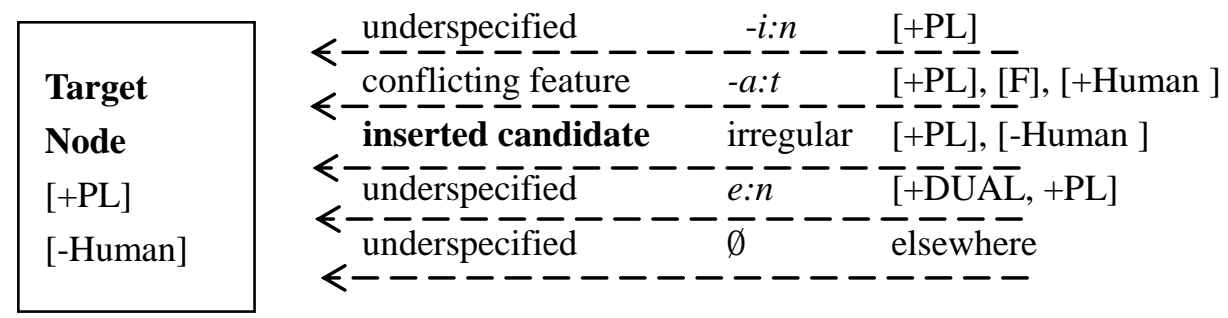

\section{Determiner Phrase}

The fourth functional head that c-commands the root is the (D)eterminer. It is proposed that D is the locus of the definiteness feature. ${ }^{16}$ Nouns in HA are either definite or indefinite. Indefiniteness is unmarked on nouns whereas definiteness is marked by the definite article prefix al- "the" which precedes all nouns except for proper nouns. Furthermore, it is argued that D in HA carries the construct state (CS) feature $[ \pm \mathrm{CS}] .{ }^{17}$ In case of a CS structure, the CS feature is [+CS]; it c-selects for a nominal complement and makes the definiteness feature of $\mathrm{D}$ undetermined $[\alpha \mathrm{DEF}]$ - that is, if the CS complement is definite, $\mathrm{D}$ is definite and if the

\footnotetext{
${ }^{16} \mathrm{D}$ is the locus for other features such as specificity and referentiality as well. However, these features are not discussed in this paper since they are not realized at Spell-Out. Moreover, it is out of the scope of this paper.

${ }_{17}$ It is believed this feature is universal and not specific to Semitic languages. Its major function is to introduce and c-select the "possessor". It is found in languages with a construction such as English. For the sake of this study, this feature will be called construct state (CS).
} 
complement is indefinite, D becomes indefinite too. In a non-CS structure, the feature is [-CS], i.e., no complement and determined definiteness feature for D. All four classes of nouns (individual, kind, group, and mass) can be $[ \pm \mathrm{DEF}]$ and $[ \pm \mathrm{CS}]$. Consider the examples in (47) for the definiteness feature:

$\begin{array}{clll}\text { (47) a. } \begin{array}{ll}\text { al-walad } \\ \text { the-boy }\end{array} & \begin{array}{l}\text { al-tuffa: } \hbar \\ \text { the-apple } \\ \text { "the boy" }\end{array} & \begin{array}{l}\text { al-fari:g } \\ \text { the-team } \\ \text { "the apples" }\end{array} & \begin{array}{l}\text { al-ruz } \\ \text { the-rice }\end{array} \\ \text { tuffa: } \hbar & \text { fari:g } & \text { "the rice" } \\ \text { b. walad } & \text { apple } & \text { team } & \text { ruz } \\ \text { boy } & \text { "apples" } & \text { "a team" } & \text { rice } \\ \text { "a boy" } & \text { brisbin } & & \\ \text { sami } & \text { Brisbane } & & \\ \text { "Sami } & \text { "Brisbane" } & \end{array}$

In (47a), all four nouns are [+DEF] and they are all preceded by the definite article. In (47b), the same nouns are bare, that is they have no article because they are [-DEF]. The proper nouns, in (47c), are also bare, although they are $[+\mathrm{DEF}]$. The tree structure in (48) is proposed to represent the formation of a full DP.

(48)

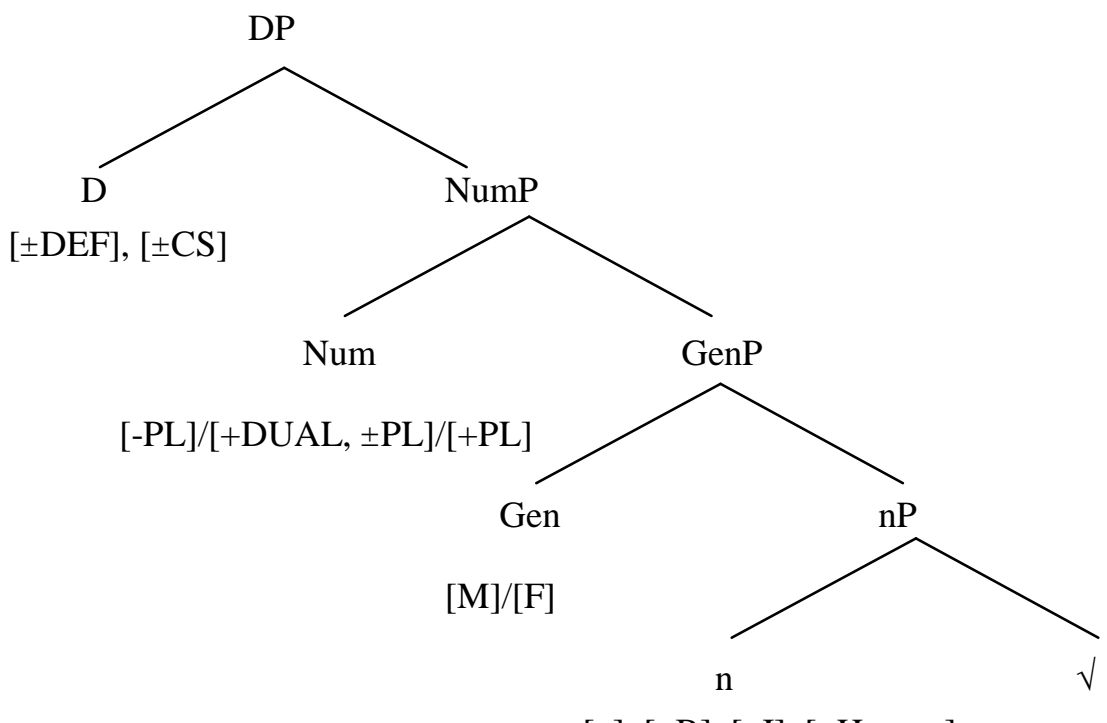

$[\mathrm{n}],[ \pm \mathrm{B}],[ \pm \mathrm{I}],[ \pm$ Human $]$

In (48), the Narrow Lexicon provides the syntax with the root, $\sqrt{ }$, and the formal features (n)ominaliser, gender, number, and definiteness. Each of the above-mentioned features is hosted under a separate functional head. The root is merged with (n)ominaliser, nP merges with Gen, GenP merges with Num which, finally, merges with D. At Spell-Out, each feature is given a separate Vocabulary Item, except for the previously discussed cases of fusion. If the noun is definite, [+DEF], its feature is realized as al- "the" at Vocabulary Insertion. If the noun is indefinite, the feature is realized as null, $\varnothing$. A derivation of the feminine dual noun, al-muddaris-at-e: $n$ "the two female teachers" is illustrated in (49).

(49) a. al-muddaris-at-e:n the-teacher-F-DUAL "the two female teachers" 
b.

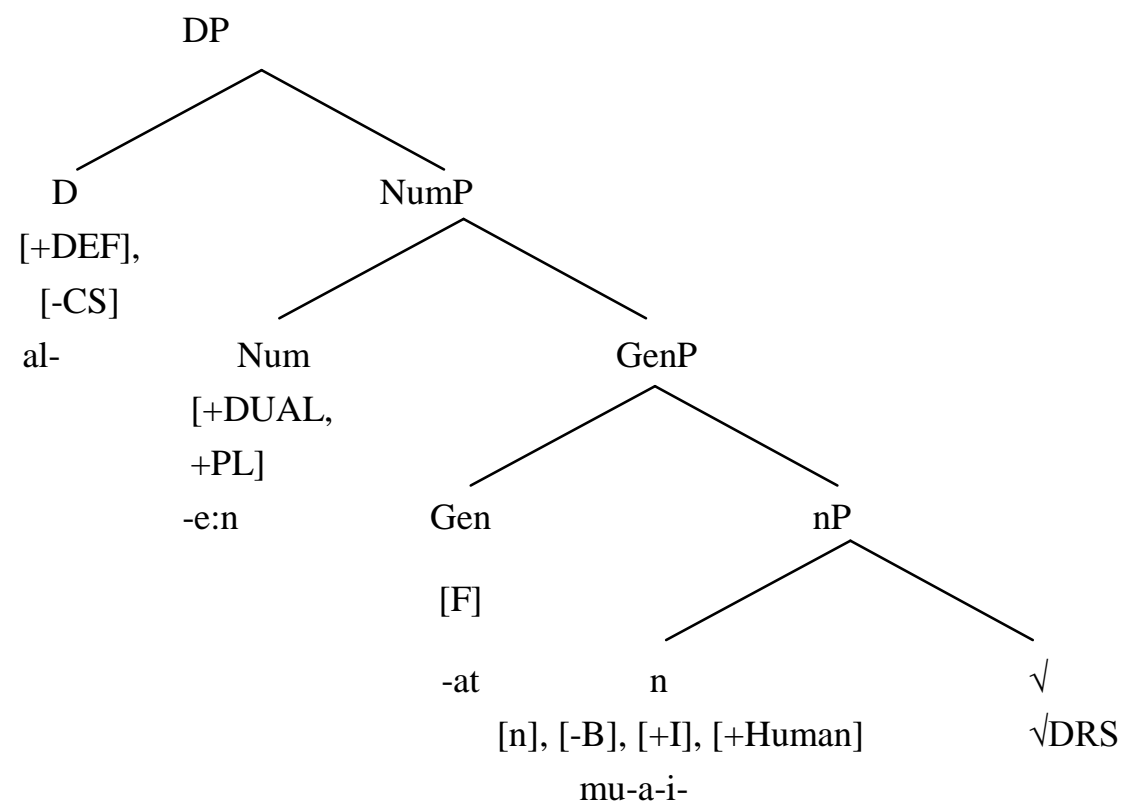

The derivation is straightforward. The root merges with the (n)ominaliser which merges with Gen. Then Gen merges with Num and, finally, NumP merges with D. At Spell-Out, each head is given a Vocabulary Item. The root is given $\sqrt{ } D R S, \mathrm{n}$ is given a templatic pattern, Gen is given the feminine marker, Num is given the dual marker, and the derivation is completed when $\mathrm{D}$ is given the definite article prefix. If the noun is indefinite, the [-DEF] feature will be given $\varnothing$.

There are two Vocabulary Items that can compete for insertion for the definiteness feature. They are:

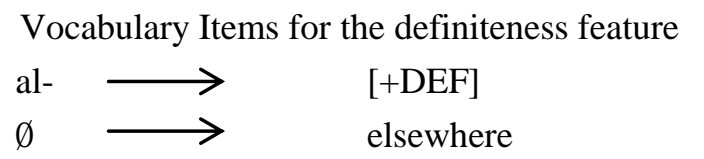

Summary

This paper begins with a brief discussion of noun classification in HA, based on Jackendoff's (1991) proposal whereby it was shown that nouns in HA belong to one of four classes: individuals, kinds, groups, and masses. The purpose of that section was to show the reader which functional heads are accepted by each of the noun classes and what effect they have. Then, the formation of simplex nouns in this Arabic variety is discussed. It is shown that nouns in HA are c-commanded by four functional heads: n, Gen, Num, and D. Since roots in DM have no formal grammatical features, it is argued that the Narrow Lexicon provides the syntax with the category-defining feature [n] along with gender, number, and definiteness features and the additional semantic classifying features in Jackendoff's system (Jackendoff, 1991). Each of these features is hosted by a separate head except for the definiteness and semantic classifying features which are hosted by $\mathrm{D}$. The four functional heads that c-command the root occur in the following order:

(51) D $>$ Num $>$ GEN $>\mathrm{n}>\sqrt{ }$

First, gender was discussed. It was shown that there are two genders in HA: masculine and feminine. Masculine is the default gender and is unmarked in contrast to feminine gender which is marked by one of two suffixes. During the derivation of feminine nouns, it is argued that feminine gender is incorporated in the noun 
in one of two ways. First, the feminine marker is added as a detachable suffix to a masculine noun (i.e., unmarked). In this case, there is no need for further morphological processes. At PF, the feminine feature is realized as the suffix - $a$. In the second case where there is no feminine marker or it cannot be separated from the noun, it is argued that Gen is fused with the (n)ominaliser at the morphology component. At the Vocabulary Insertion stage, one Vocabulary Item is given for both of them.

Then, number was discussed. In HA, nouns can be singular, dual, or plural. Singular is the default number and it is unmarked. Dual and plural are marked either with a suffix (dual and grammatical plural) or with a vowel pattern (broken plural) in which the consonantal root of the singular noun is fitted. It is argued that in the case of dual and sound masculine plural, there are no morphological processes on the derivation. However, in the case of the sound feminine plural and the broken plural, there is fusion between Num and Gen (sound feminine plural) or between Num and the (n)ominaliser (broken plural).

Finally, it was shown that $\mathrm{D}$ is the locus of the definiteness feature and CS feature. $[+\mathrm{DEF}]$ is realized as the definite article al- "the" whereas [-DEF] is not marked. CS feature is responsible for c-selecting the CS complement and the definiteness feature of $\mathrm{D}$ being undetermined.

It was shown in the discussion of the different functional heads that the semantic feature under $\mathrm{n}$ and the gender and number features can affect the derivation of the noun and the Vocabulary Items that compete for insertion.

\section{References}

Abney, S. P. (1987). The English noun phrases in its sentential aspect (Ph.D., MIT).

Bernstein, J. (1991). DPs in French and Walloon: Evidence for parametric variation in nominal head movement. Probus, 3, 1-26.

Bernstein, J. (1993). The syntactic role of word markers in null nominal constructions. Probus, 5, 5-38.

Bernstein, J. (2001). The DP hypothesis: Identifying clausal properties in the nominal domain. In M. Baltin and C. Collins (Eds.), The handbook of contemporary syntactic theory (pp. 536-561). Oxford: Blackwell.

Chierchia, G. (1985). Formal semantics and the grammar of predication. Linguistic Inquiry, 16, 417-443.

Chierchia, G. (1998). Reference to kinds across languages. Natural Language Semantics, 6, 339-405.

Embick, D. (2010). Localism versus globalism in morphology and phonology. Cambridge: MIT Press.

Embick, D., \& Noyer, R. (2007). Distributed morphology and the syntax-morphology interface. In G. Ramchand and C. Reiss (Eds.), The Oxford handbook of linguistic interfaces (pp. 289-324). Oxford: Oxford University Press.

Fassi Fehri, A. (2005a). Nominal classes, reference, and functional parameters, with particular reference to Arabic. In P. Pica (Ed.), Linguistic variation yearbook 2004 (pp. 41-108). Amsterdam: John Benjamins Publishing Company.

Fassi Fehri, A. (2005b). Verbal and nominal parallelisms. Documents \& Reports, 8, 1-22.

Fassi Fehri, A. (2012). Key features and parameters in Arabic grammar. Amsterdam/Philadelphia: John Benjamins.

Halle, M., \& Marantz, A. (1993). Distributed morphology and the pieces of inflection. In K. Hale and S. J. Keyse (Eds.), The view from Building 20: Essays in linguistics in honor of Sylvain Bromberger (pp. 111-176). Cambridge: MIT Press.

Halle, M. \& Marantz, A. (1994). Some key features of Distributed Morphology. In A. Carnie \& H. Harley (Eds.), MIT Working Papers in Linguistics 21: Papers on phonology and morphology (pp.275-288). Cambridge, Mass.: MITWPL.

Harley, H., \& Noyer, R. (1999). State-of-the-article: Distributed morphology. Glot International, 4(4), 3-9.

Harley, H., \& Noyer, R. (2000). Formal versus encyclopedic properties of vocabulary: Evidence from nominalisations. In B. Peters (Ed.), The lexicon-encyclopedia interface (pp. 349-374). Amsterdam: Elsevier.

Haugen, J. D., \& Siddiqi, D. (2013). Roots and the derivation. Linguistic Inquiry, 44(3), 493-517.

Jackendoff, R. (1991). Parts and boundaries. Cognition, 41, 9-45.

Kremers, J. M. (2003). The Arabic noun phrases: A minimalist approach (Ph.D., University of Nijmegen).

Longobardi, G. (1994). Reference and proper names: A theory of N-movement in syntax and logical form. Linguistic Inquiry, 25(4), 609-665.

Longobardi, G. (2001). The structure of DPs. In M. Baltin and C. Collins (Eds.), The handbook of contemporary syntactic theory 
(pp. 562-603). Oxford: Blackwell.

Marantz, A. (1997). No escape from syntax: Don't try morphological analysis in the privacy of your own lexicon. University of Pennsylvania Working Papers in Linguistics, 4, 201-225.

McCarthy, J., \& Prince, A. (1990a). Foot and word in prosodic morphology: The Arabic broken plural. Natural Language and Linguistic Theory, 8, 209-283.

McCarthy, J., \& Prince, A. (1990b). Prosodic morphology and templatic morphology. In M. Eid and J. McCarthy (Eds.), Perspectives on Arabic linguistics II (Vol. 72, pp. 1-54). Amsterdam/Philadelphia: John Benjamins.

Partee, B. H. (1986). Noun phrase interpretation and type-shifting Principles. In J. Groenendijk, D. D. Jongh, and M. Stokhof (Eds.), Studies in discourse representation theory and the theory of generalized quantifiers (pp. 115-143). Dordrecht: Foris.

Pfau, R. (2000). Features and categories in language production (Ph.D., University of Frankfurt).

Pfau, R. (2009). Grammar as processor: A distributed morphology account of spontaneous speech errors. Amsterdam: Benjamins.

Picallo, M. C. (1991). Nominals and nominalizations in Catalan. Probus, 3, 279-316.

Ratcliffe, R. R. (1998). The "broken" plural problem in Arabic and comparative semitic. Amsterdam/Philadelphia: John Benjamins.

Ritter, E. (1991). Two functional categories in noun phrases: Evidence from Modern Hebrew. In Rothstein, S. (ed.), Syntax and semantics: Perspectives on phrase structure. (Vol. 25, pp. 37-62). San Diego: Academic Press.

Ritter, E. (1992). Cross-linguistic evidence for number phrase. Canadian Journal of Linguistics/Revue Canadienne de Linguistique, 37, 197-218.

Ritter, E. (1993). Where's gender? Linguistic Inquiry, 24(4), 795-803.

Ryding, K. C. (2005). A reference grammar of modern standard Arabic. Cambridge: Cambridge University Press.

Siddiqi, D. (2006). Minimize exponence: Economy effects on the morphosyntactic component of the grammar (Ph.D., University of Arizona).

Siddiqi, D. (2009). Syntax within the word: Economy, allomorphy, and argument selection in distributed morphology. Amsterdam/Philadelphia: John Benjamins Publishing Company. 